\title{
La conservación: el porvenir del pasado
}

Philip R. Ward

El presente artículo ha sido extraído de la revista MUSEUM (Copyright. UNESCO 1982. Reproduced by permission of UNESCO), a cuya dirección queremos agradecer la colaboración prestada. Hacemos también ésta extensiva al autor, con la indicación expresa de que la idea central del artículo procede de una publicación para el Museo Provincial de Columbia Británica, Vancouver, Canadá.

odo lo que realmente conocemos sobre nosotros mismos y sobre nuestro mundo proviene del pasado. Y todo lo que conocemos verdaderamente del pasado es aquella parte que ha sobrevivido bajo la forma de objetos materiales. Solamente una pequeña fracción de nuestra historia está consignada en la literatura y la literatura está sujeta a los errores de interpretación humanos. Sólo los especímenes materiales de la historia natural y humana son indiscutibles, ya que son la materia prima de la historia, los hechos innegables. La verdad sobre el pasado. La conservación es el medio a través del cual los preservamos. Es un acto de fe en el futuro.

La principal tarea de un museo es preservar aquellos objetos del pasado que están a su cargo para las generaciones presentes $y$ futuras.

Los objetos que preservamos no han sido destruidos por el tiempo, ya que el tiempo, por sí solo, rara vez destruye. Por una u otra casualidad milagrosa han sobrevivido, a menudo por cientos de años, algunas veces por miles de años, al fuego, la tempestad y los terremotos, a las guerras, el robo y el vandalismo pero, sobre todo, a nuestra propia negligencia.

Frecuentemente, corren más peligro en un edificio moderno que en ningún otro periodo de sus vidas: temperaturas variables, exceso o falta de humedad, radiaciones ultravioletas, insectos, gases atmosféricos y malos tratos pueden destruir lo que la naturaleza ha salvado. Los protegemos contra estos peligros utilizando un conjunto de técnicas que denominamos conservación.

\section{Conservación y estudio}

Los restauradores se guían por el precepto médico siguiente: un tratamiento es correcto cuando el diagnóstico es correcto. Un diagnóstico acertado se obtiene por medio del examen técnico y profundo de un objeto, para lo cual contamos con muchos medios científicos modernos, pero los elementos más importantes siguen siendo la experiencia y la capacidad de interpretación del examinador.

Muchos exámenes tienden a identificar el origen del deterioro y a dar una orientación para un tratamiento adecuado. Sin embargo, en ciertas ocasiones es necesario realizar investigaciones y estudios. Cuando un museo adquiere un objeto o cuando desea prestarlo o usarlo en alguna forma especial, éste es examinado para establecer y anotar cuál es su estado, y determinar las zonas de vulnerabilidad potencial que puedan requerir cuidados especiales en el futuro. A menudo, dichos estudios proporcionan información acerca de la edad del objeto, de qué manera fue producido y cómo fue usado. Dichos estudios pueden incluso revelar irregularidades que indican si se trata de una falsificación o si ha sido excesivamente restaurado.

\section{Conservación y comportamiento de los materiales}

Cualquier objeto, absolutamente cualquier objeto, desde una punta de flecha de silex a una nave espacial, desde una piragua al barco Queen Mary, puede terminar en un museo y el museo debe saber cómo cuidar de él.

Esto significa que un restaurador debe saber tratar cualquier tipo de materia que haya sido trabajada por el hombre. Para hacerlo con éxito, debe conocer cómo se comportan estas materias en diversas circunstancias. Debe poder predecir su respuesta al medio ambiente del museo y saber cómo tratar los factores que puedan causar daños.

\section{Conservación y control del medio ambiente}

El museo es un edificio dentro del cual las colecciones están sometidas a un microclima artificial, y 
donde la temperatura, la humedad, los rayos ultravioletas y la actividad electrolítica, biológica y química, unidos a la suciedad y las perturbaciones causadas por las actividades humanas, crean un sistema ecológico complejo de fuerzas interrelacionadas. El conocimiento y el control de dichas fuerzas constituye el aspecto más importante y difícil de la ciencia de la conservación.

La temperatura del museo es importante porque el calor acelera la actividad química, biológica y, sobre todo, porque normalmente origina una disminución de la humedad. Si el aire es muy seco, el cuero se endurece, el papel y el mimbre se resquebrajan, la madera se comprime y se achica. Si es muy húmedo, el moho hará su aparición en el cuero y el papel, hongos e insectos afectarán la madera y los metales sufrirán corrosión.

La exposición a los rayos ultravioletas de la luz del día o de las luces fluorescentes hará que los colores destiñan y que las materias orgánicas se vuelvan fiables.

El dióxido de sulfuro y otros gases presentes en la atmósfera urbana decolorarán los pigmentos y corroerán el metal y la piedra.

El polvo y el hollín mancharán las materias sensibles, provocarán un comienzo de corrosión en las demás y afectarán casi cualquier cosa.

Los insectos y los roedores pueden causar grandes daños en las colecciones de museo. Deben controlarse por medio de la vigilancia y aseo de las zonas de almacenamiento y por medio del examen y de la fumigación de las nuevas adquisiciones. La aparición de insectos dañinos en los museos no es producto del azar. Resultan difíciles controlar debido a que la eficacia del tratamiento utilizado depende básicamente del conocimiento que se tenga sobre sus ciclos de vida.

El medio ambiente del museo constituye, en efecto, un sistema ecológico artificial cuyo delicado equilibrio debe ser mantenido. El efecto de cualquier cambio ambiental, producido de manera accidental o por las medidas adoptadas para corregirlo, debe ser cuidadosamente considerado en función de todas las fuerzas del sistema. Una solución negligente o inconsecuente a un pequeño problema puede provocar uno mucho mayor.

\section{Conservación y almacenamiento}

Algunos objetos pueden ser almacenados sobre repisas o en cajones o cómodas, pero muchos de ellos requieren encerramientos (sic) o soportes especiales. Algunos no poseen una superficie lisa sobre la cual reposar o no soportan su propio peso. Otros presentan extremidades frágiles que pueden quebrarse o doblarse si el objeto se apoya en ellas.

Para prevenir el deterioro de los objetos debido al almacenamiento o la exposición, se diseñan y construyen estructuras especiales.

\section{Conservación y manipulación}

Una de las principales razones para preservar los objetos en los museos es la de asegurar que éstos estén disponibles para el estudio; y estudio implica manipulación. Además, constantemente los museos renuevan sus exposiciones, mejoran sus áreas de almacenamiento o prestan objetos a otros museos. Todo esto implica movimiento y manipulación. La destreza para manejar las colecciones con cuidado es quizá la cualidad fundamental del empleado de un museo.

En primer lugar hay que considerar el material del cual está hecho el objeto: ¿Es flexible o frágil? ¿Es quebradizo? ¿Es duro o suave? ¿Se lo puede aplastar? ¿Se raya fácilmente? ¿Puede ser manchado o marcado por sus manos? ¿Cómo está construido? ¿Es demasiado pesado o grande para ser levantado? ¿Hay un colaborador disponible? Si es así, ¿cree que entiende lo que usted está haciendo? ¿Dónde colocará el objeto?.

En segundo lugar, hay que considerar su forma y reflexionar sobre lo que ésta implica en términos de movimiento: ¿Es largo o delgado? ¿Es redondo? ¿Rectangular? ¿Dónde está su centro de gravedad? ¿De dónde se lo puede asir sin riesgos? ¿Cómo puede ser colocado?.

\section{Conservación y transporte}

Debido al valor y a la fragilidad de muchos objetos de museo, existe cierta reticencia a someterlos a los peligros de un viaje, y muchos museos se niegan categóricamente a prestarlos. Sin embargo, muchas piezas de museo son objeto de préstamo y hay un número creciente de exposiciones itinerantes que están constantemente "en ruta". El diseño y la construcción de embalajes especiales son tareas complejas. El embalaje de objetos de arte lleva implícita la noción de "suspensión". Los principios del diseño de embalajes encuentra su mejor ilustración en el embrión: el sujeto frágil está sostenido y protegido contra golpes por un medio -controlador del medio ambiente- generalmente líquido, flexible, dentro de un caparazón impenetrable y resistente. Para los objetos de arte, no siempre es posible utilizar un soporte líquido, aunque a veces utilizamos aire, los principios generales son los mismos.

Se debe tener sumo cuidado en la selección de los materiales de embalaje; éstos deben ser flexibles, pero en modo alguno deben dañar el objeto. Se debe considerar si pueden manchar el objeto (papel de periódico), si son ácidos (papel de pulpa de madera y otros derivados de la madera), si pueden desprender gases dañinos o estimular la condensación (algunos plásticos), o si pueden contener o atraer insectos (lanas y otros productos orgánicos).

Finalmente, el método de transporte debe ser rigurosamente seleccionado para disminuir su duración y las manipulaciones bruscas. Pero no siempre es posible preparar el transporte con el cuidado necesario. Así, puede suceder que se descubran objetos en lugares muy alejados; entonces es preciso, a partir de los ele- 
mentos disponibles, improvisar un embalaje que, a la vez que constituya "un colchón" elástico, permita proteger el contenido contra los cambios climáticos.

\section{Conservación y tratamiento}

Muchos de los objetos encontrados en el terreno nos llegan en condiciones precarias. Aún más numerosos son los que se desintegrarán rápidamente al entrar en contacto con un medio ambiente nuevo, a menos que se intervenga a tiempo.

Por ejemplo, materias orgánicas muy frágiles pueden sobrevivir durante miles de años enterradas en un terreno impregnado de agua. Cuando son descubiertas, su apariencia es la que tenían cuando fueron enterradas pero, en realidad, pueden encontrarse a un paso de la desintegración. Las miríadas de pequeñas células que componen la madera pueden haber sufrido la erosión a tal punto, que sólo el agua que contienen cuando se las descubre las mantiene unidas. Ese agua comenzará a evaporarse en el momento en que el objeto sea expuesto y las células a desintegrarse.

Esto puede impedirse inyectando en el objeto un producto que reemplazará al agua y mantendrá las células unidas. La sustancia más comúnmente utilizada para consolidar la materia orgánica impregnada de agua es el glicol polietileno, que es una cera soluble en agua.

\section{Conservación y limpieza}

El polvo no tiene ningún valor estético ni histórico, pero limpiar un objeto no es una cuestión tan simple como parece. Es fundamental distinguir entre la suciedad que debe ser eliminada porque puede esconder el color y los detalles originales y precipitar el deterioro, y la pátina que debe ser preservada porque puede contener indicios de la historia del objeto y de su edad. La limpieza de las antigüedades es una operación altamente técnica que debe ser cuidadosamente controlada porque casi siempre produce abrasión en la superficie del objeto. Por leve que sea esta abrasión, la limpieza repetida multiplicará su efecto y puede ocasionar un serio desgaste. Cada vez que se limpia un objeto, se pierde una pequeña parte de su superficie y se modifica su aspecto original. Sin embargo, esta limpieza es a veces necesaria y puede ser urgente cuando hay un grave deterioro. En estos casos, el objeto debe ser limpiado para estabilizarlo y prevenir un estrago aún mayor.

\section{Conservación y reparación}

Muchos de los objetos que los museos reciben presentan algún tipo de daño, mientras que otros que han permanecido en museos por varios años, a menudo en condiciones precarias, pueden haberse deteriorado.

Puede ser necesario repararlos para prevenir un estrago mayor, permitir que sean manipulados con fines de estudio o para que puedan ser expuestos o prestados. Probablemente ninguna otra área de la conservación presenta tantas dificultades, siendo las menores de entre ellas las de tipo técnico. Nuestros métodos y materiales han progresado constantemente y por ahora quedan sólo unas pocas dificultades técnicas insolubles. Pero se siguen planteando problemas éticos.

Cuando una pieza dañada es reparada, ihasta qué punto debe ser restaurada? Si falta una parte, isabemos cómo era el original? Y aun así, ipodemos reemplazarlo? Puede que no se haya desprendido accidentalmente, y si así fuera, ¿no constituye esto un acontecimiento significativo de su historia? ¿Estamos seguros de que el "daño" que estamos reparando no es el resultado de su uso legítimo o de una modificación deliberada, que puede ser un importante indicio de la forma como el objeto era utilizado?

¿Debemos concebir nuestra restauración en función de hacer aparecer el objeto como lo más perfecto posible? O, ¿debemos dejarla aparente para no desilusionar a nuestros futuros académicos?

¿Debemos reemplazar las partes que faltan con los que creemos eran los materiales originales o con materiales notoriamente diferentes?

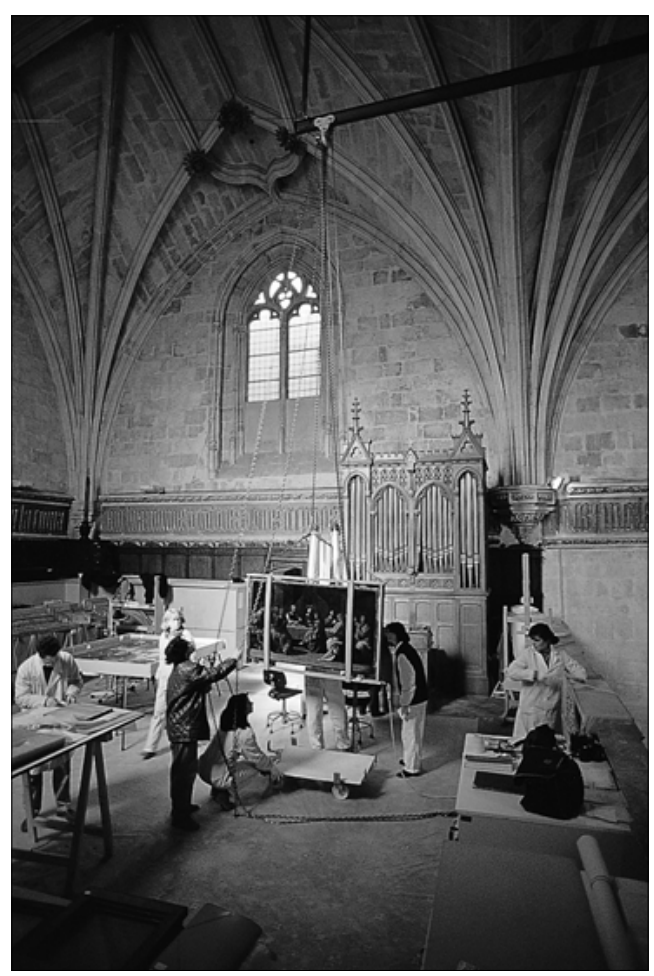

\section{Conservación y trabajo sobre el terreno}

Todas estas técnicas están encaminadas a un fin: la preservación de objetos de arte por medio de su estabilización para prevenir un deterioro mayor.

Normalmente esto se hace en el museo, pero hay ciertos objetos que no pueden o no deben ser trasladados y deben ser tratados in situ. Éste es a menudo el caso de grandes estructuras: edificios, totems y muchos descubrimientos arqueológicos.

Este aspecto interesante e inusitado de la conservación requiere experiencia y habilidades que no siempre se le exigen a un restaurador. La habilidad para improvisar y trabajar en condiciones difíciles, algunas veces sin contar con ayudas mecánicas, es a veces más importante que el conocimiento científico.

Traducido del inglés para la revista Museum 